\title{
Stiffness Problem Identified
}

National Cancer Institute

\section{Source}

National Cancer Institute. Stiffness Problem Identified. NCI Thesaurus. Code C92118.

Problems that occurred when its material is either too flexible/pliable or inflexible/rigid when in contact by an applied force. 